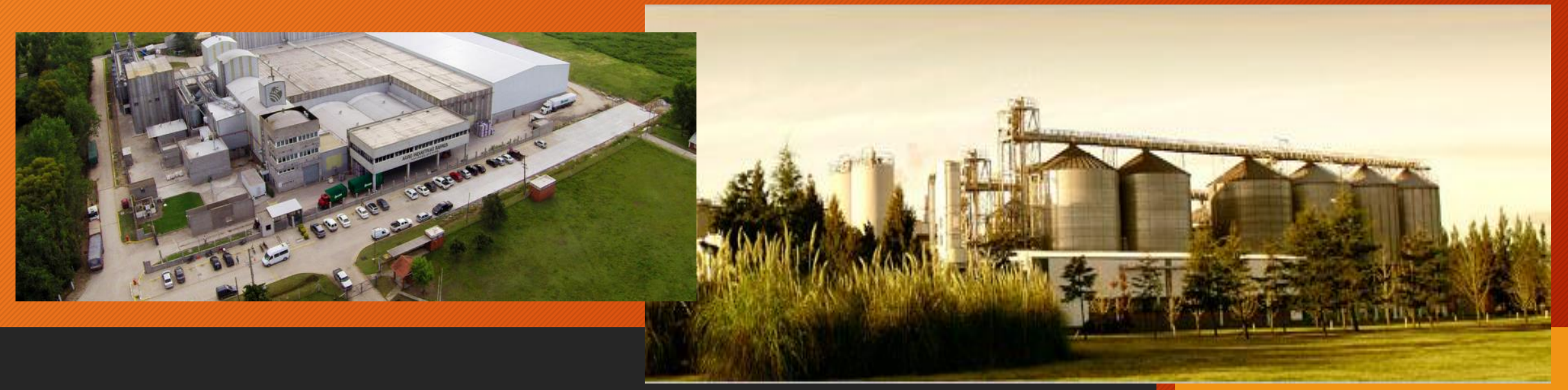

\title{
LOS SISTEMAS AGROINDUSTRIALES EN ARGENTINA Y EL NEA
}

Prof. Alejandra Torre Geraldi Profesorado y Licenciatura en Geografía

Facultad de Humanidades- UNNE

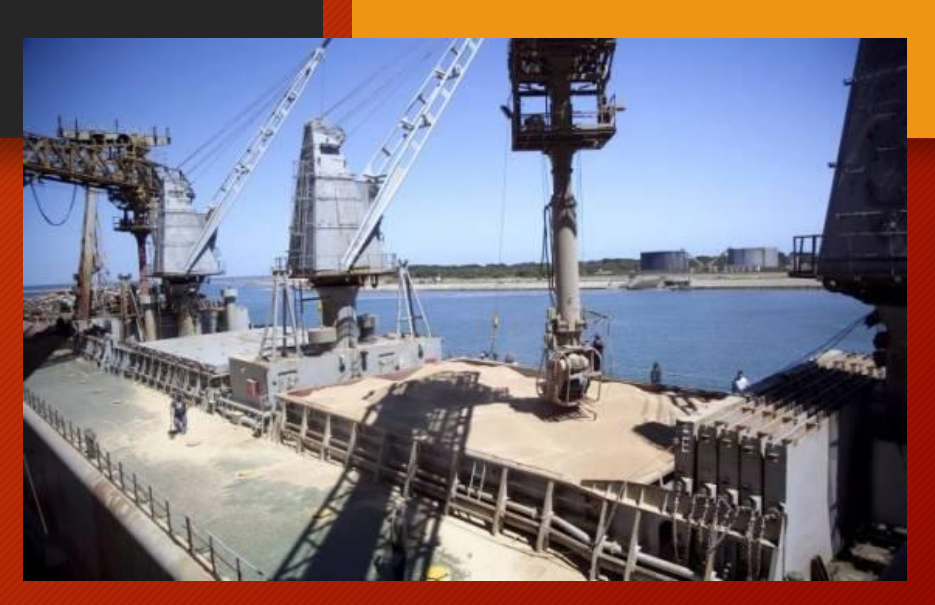

Publicado en formato digital: Prof. Alejandra H. Torre Geraldi. LOS SISTEMAS AGROINDUSTRIALES EN ARGENTINA Y EL NEA

Producción en docencia. Revista Geográfica Digital. IGUNNE. Facultad de Humanidades. UNNE. Año 13. № 26. Julio -Diciembre 2016. Resistencia, Chaco. En: http://hum.unne.edu.ar/revistas/geoweb/default.htm 


\section{LOS SISTEMAS AGROINDUSTRIALES EN ARGENTINA Y EL NEA}

- La presentación en power point, es una elaboración propia, generada a partir de la bibliografía escrita e información en formato digital.

- Material de Síntesis para los alumnos del Profesorado y de la Licenciatura en Geografía de la UNNE. 


\section{LAS AGROINDUSTRIAS}
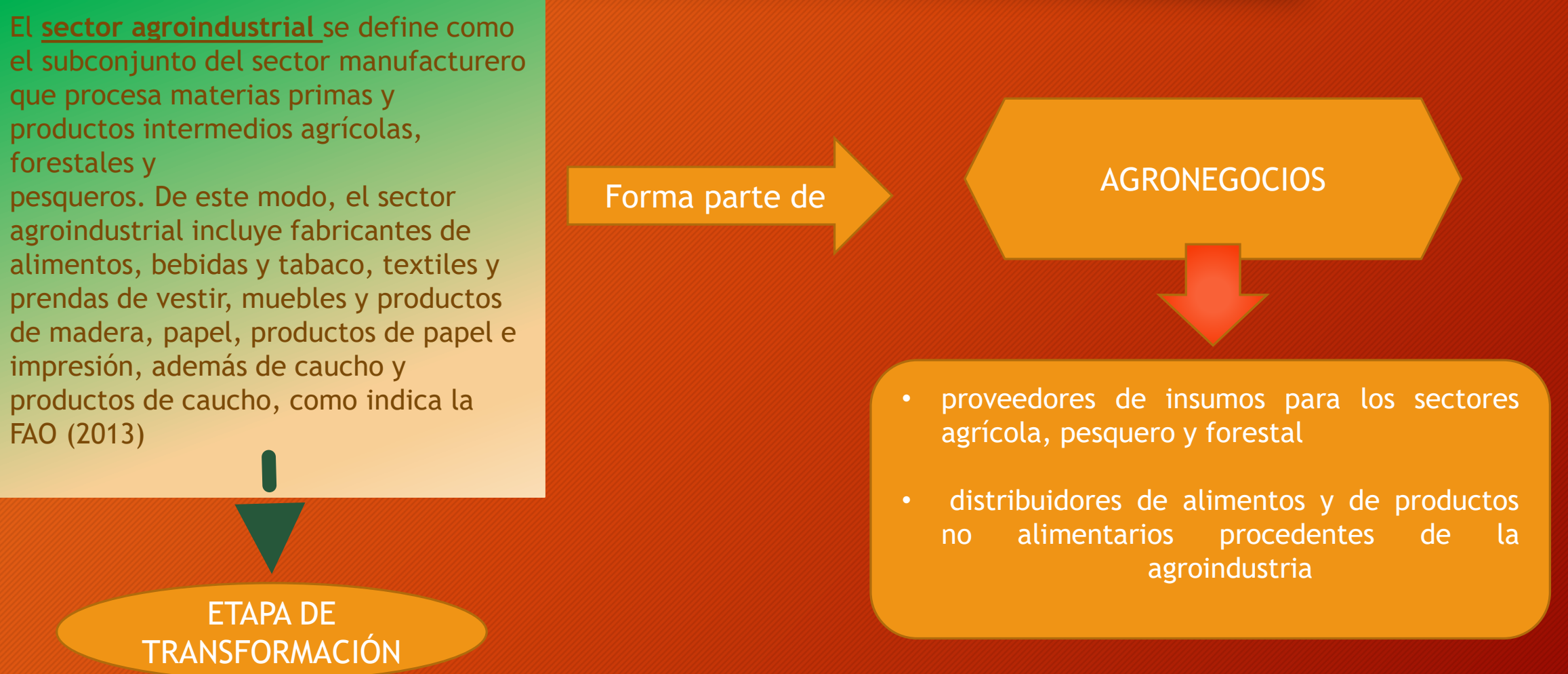

Publicado en formato digital: Prof. Alejandra H. Torre Geraldi. LOS SISTEMAS AGROINDUSTRIALES LAS AGROINDUSTRIAS EN ARGENTINA Y EL NEA Producción en docencia. Revista Geográfica Digital. IGUNNE. Facultad de Humanidades. UNNE. Año 13. № 26. Julio -Diciembre 2016. Resistencia, Chaco. En: http://hum.unne.edu.ar/revistas/geoweb/default.htm 


\section{Crecimiento de la Agroindustria}
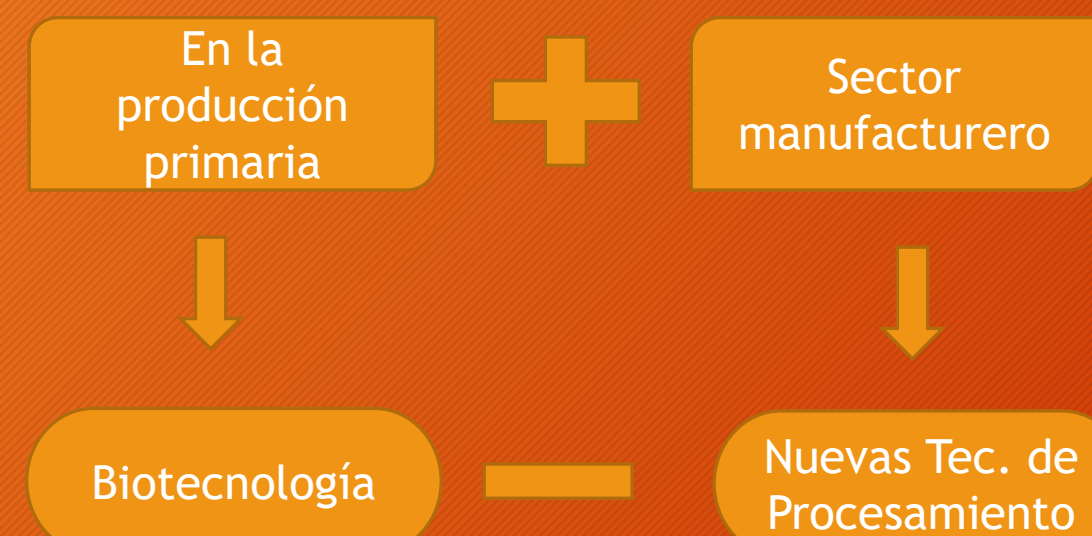

Nuevas Tec. de Procesamiento
Innovación y procesos.

- Mejorar la Productividad.

- Normas de Calidad.

- Vínculos verticales y horizontales.

- Mayor Valor Agregado.

- Incremento de la demanda.

Temor de quedarse atrás y no poder acceder a nuevos insumos y tecnologías
Posicionamiento en el Mercado

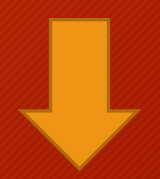

El productor no puede salir a vender lo que produjo, sino a producir lo que tiene mercado de compra (Alvarado Ledesma, 2004)

“En una producción competitiva, el trabajo será realizado en su mayor parte por trabajadores del saber que tengan las máquinas a su servicio" (Drucker, Peter. En Alvarado Ledesma, 2004)

Publicado en formato digital: Prof. Alejandra H. Torre Geraldi. LOS SISTEMAS AGROINDUSTRIALES LAS AGROINDUSTRIAS EN ARGENTINA Y EL NEA Producción en docencia. Revista Geográfica Digital. IGUNNE. Facultad de Humanidades. UNNE. Año 13. № 26. Julio -Diciembre 2016. Resistencia, Chaco. En: http://hum.unne.edu.ar/revistas/geoweb/default.htm 


\section{El Sistema Agroindustrial}

* La visión económica tradicional de la República Argentina ve a la producción agraria como una actividad que nace y muere en el ámbito rural (Cf. Alvarado Ledesma, 2004).

Aparece el concepto de cadena de valor que engloba todos los vínculos existentes entre todas las actividades que luego dan como resultado productos para satisfacer las necesidades del mercado.
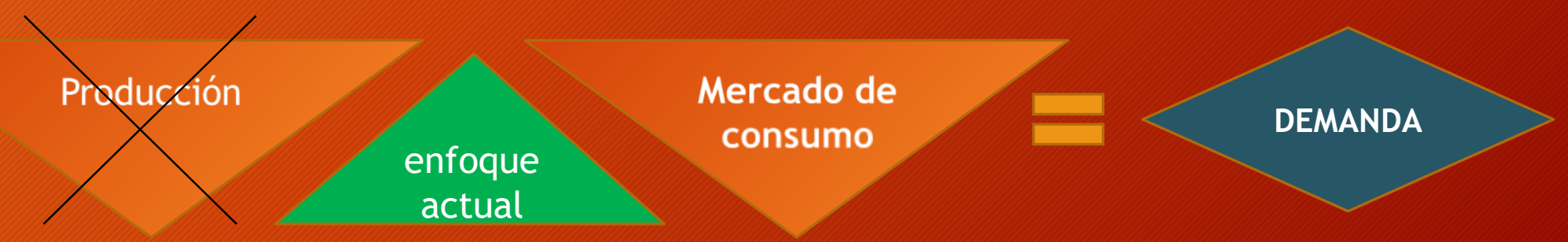

Publicado en formato digital: Prof. Alejandra H. Torre Geraldi. LOS SISTEMAS AGROINDUSTRIALES LAS AGROINDUSTRIAS EN ARGENTINA Y EL NEA Producción en docencia. Revista Geográfica Digital. IGUNNE. Facultad de Humanidades. UNNE. Año 13. № 26. Julio -Diciembre 2016. Resistencia, Chaco. En: http://hum.unne.edu.ar/revistas/geoweb/default.htm 


\section{El Sistema Agroindustrial}

\section{El Sistema Agroindustrial}

Industrias de
insumos y bienes
de Capital +
Servicios Invest. y
Desarrollo

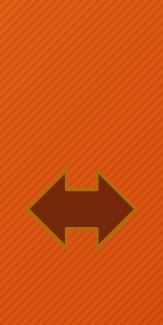

\section{Agroindustrias}

(preservación, conservación, transformación)
Distribución, Comercialización

Mayor interrelación de la empresa agrícola y su contexto económico- político y social tanto a nivel nacional como global.

$\checkmark$ Industrialización de la agricultura (diferenciación productos- tecnificación productiva y cuidado del medio ambiente).

$\checkmark$ Menor peso de la materia prima en el precio final.

$\checkmark$ Diferenciación de productores: estructuras de producción cada vez más heterogéneas.

$\checkmark$ Asimetría de las relaciones. 


\section{Complejo o Sistema Agroindustrial Argentino}

Se define al complejo agroindustrial como un conjunto de actividades agropecuarias, pesquera y forestal y a la producción agroindustrial. (Obschatko; 1994) que contempla el proceso de transformación y salida al mercado.

Mientras que Martinez de Ibarreta; Posadas y Pucciarelli (1994) lo analizan como un complejo multidisciplinario que articula formas organizativas del conjunto de relaciones productivas, sociales y tecnológicas que se desarrollan en un espacio micro y macroeconómico.

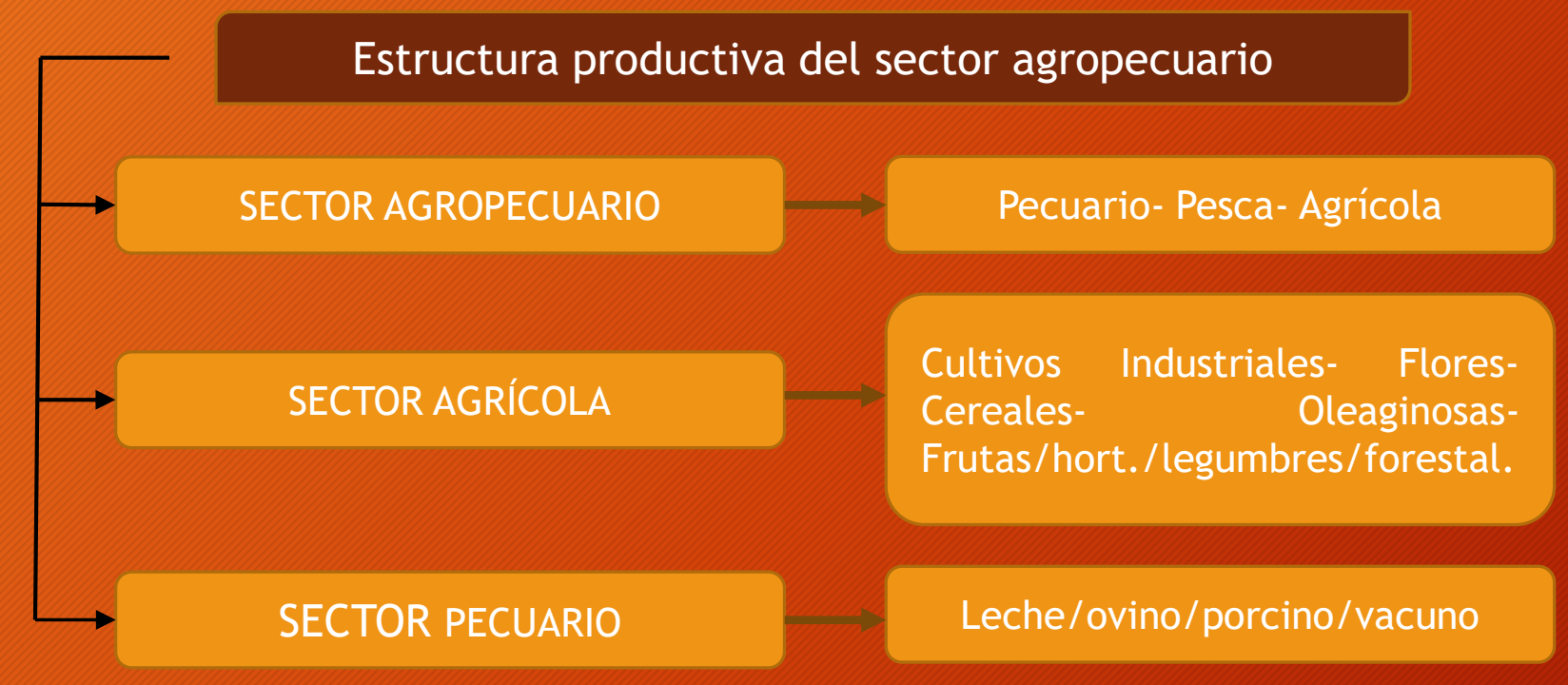

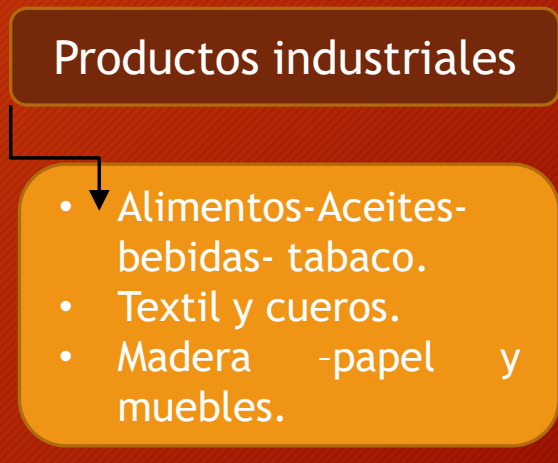

Fuente: Obschatko; 1994: 6-8.

Publicado en formato digital: Prof. Alejandra H. Torre Geraldi. LOS SISTEMAS AGROINDUSTRIALES LAS AGROINDUSTRIAS EN ARGENTINA Y EL NEA Producción en docencia. Revista Geográfica Digital. IGUNNE. Facultad de Humanidades. UNNE. Año 13. № 26. Julio -Diciembre 2016. Resistencia, Chaco. En: http://hum.unne.edu.ar/revistas/geoweb/default.htm 


\section{Sistema agroindustrial y clusters}

- En la actualidad, cuando hablamos de sistemas agroindustriales vamos a asociarlos al término "Clusters".

-Joseph Ramos (1998: 164), de la Comisión Económica para América Latina (CEPAL), concibe al cluster como "una concentración sectorial y/o geográfica de empresas en las mismas actividades o en actividades estrechamente relacionadas con importantes economías externas y acumulativas, de aglomeración y especialización de productores, proveedores y mano de obra especializada de servicios anexos específicos del sector-, con la posibilidad de acción conjunta en busca de la eficiencia colectiva".

-Michael Porter (1999: 165) entiende que "los clusters son concentraciones geográficas de empresas e instituciones interconectadas que actúan en determinada área" Para Porter los clusters alientan la competencia y la cooperación y el vínculo informal entre las empresas y las instituciones.

-Alvarado Ledesma (2004: 169) señala que "el cluster es una agrupación de agentes económicos que participan en forma directa (cadena productiva) o indirecta (industrias conexas) en la creación de productos finales.

Publicado en formato digital: Prof. Alejandra H. Torre Geraldi. LOS SISTEMAS AGROINDUSTRIALES LAS AGROINDUSTRIAS EN ARGENTINA Y EL NEA Producción en docencia. Revista Geográfica Digital. IGUNNE. Facultad de Humanidades. UNNE. Año 13. № 26. Julio -Diciembre 2016. Resistencia, Chaco. En: http://hum.unne.edu.ar/revistas/geoweb/default.htm 


\section{Etapas de maduración de un Cluster}

- Como todo proceso, los clusters poseen distintos estadios de maduración, para ello deben atravesar diferentes etapas. Joseph Ramos, en el Reporte Industrial 1999 distingue cuatro fases de madurez que a continuación pasan a detallarse:

- En una primera fase se extrae y exporta el producto natural con un mínimo de procesamiento doméstico.

- En la segunda fase, comienzan las actividades de procesamiento y exportaciones, asimismo se da inicio a la sustitucion de las importaciones y se producen insumos nacionales.

- En la tercera fase se exportan bienes y servicios que inicialmente habían sido sustituidos, y se profundiza la exportación de productos procesados cada vez mas sofisticados.

- La cuarta y última fase es alcanzada cuando se exporta todo, tanto los productos procesados como los insumos, maquinarias y servicios empresariales. 


\section{Fases Productivas}

\begin{tabular}{|c|c|c|c|c|}
\hline & FASE I & FASE II & FASE III & FASE IV \\
\hline 1. Exportaciones & Recurso natural en bruto & Primer nivel de procesamiento & $\begin{array}{l}\text { Procesamiento más especializado } \\
\text { de primer nivel. } \\
\text { Segundo nivel de procesamiento }\end{array}$ & Inversión en el exterior \\
\hline 2.Insumos & Importados & $\begin{array}{l}\text { Sustitución de importaciones de insumos } \\
\text { principales para mercado nacional }\end{array}$ & Exportación de insumos & Exportación de insumos \\
\hline 3.Maquinarias & $\begin{array}{l}\text { Importados (reparación } \\
\text { local) }\end{array}$ & $\begin{array}{l}\text { Producción bajo licencia para mercado } \\
\text { nacional }\end{array}$ & $\begin{array}{l}\text { Exportación de maquinarias } \\
\text { básicas a mercados menos } \\
\text { sofisticados. } \\
\text { Desarrollo de equipos más } \\
\text { especializados }\end{array}$ & $\begin{array}{l}\text { Exportación de maquinarias de } \\
\text { todo tipo a mercados sofisticados }\end{array}$ \\
\hline $\begin{array}{l}\text { 4. Ingeniería } \\
\text { a. Producción }\end{array}$ & Semi importada & Nacional & Nacional & Nacional \\
\hline $\begin{array}{l}\text { b. Dueño de } \\
\text { proyecto }\end{array}$ & Importada & Parcial nacional & Nacional & Exportación \\
\hline c. Consultoría & Importada & Parcial Nacional & Nacional salvo especialidades & Exportación \\
\hline
\end{tabular}

Fuente: Reporte Industrial 1999. http://www.oocities.org/wallstreet/exchange/1033/ri99.htm

Publicado en formato digital: Prof. Alejandra H. Torre Geraldi. LOS SISTEMAS AGROINDUSTRIALES LAS AGROINDUSTRIAS EN ARGENTINA Y EL NEA Producción en docencia. Revista Geográfica Digital. IGUNNE. Facultad de Humanidades. UNNE. Año 13. № 26. Julio -Diciembre 2016. Resistencia, Chaco. En: http://hum.unne.edu.ar/revistas/geoweb/default.htm 


\section{Divisiones Básicas de un Cluster}

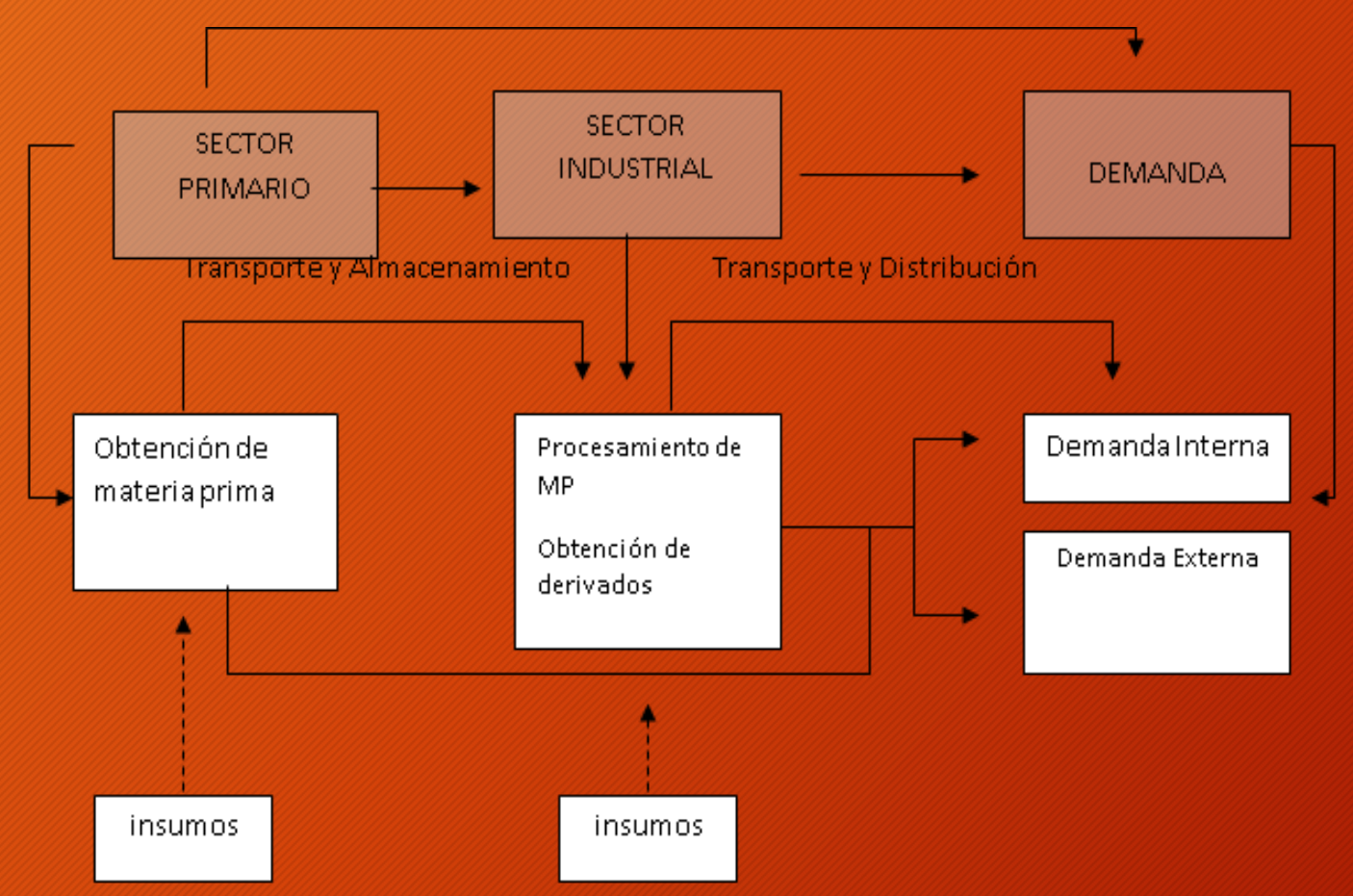

Fuente: Elaboración Propia

Publicado en formato digital: Prof. Alejandra H. Torre Geraldi. LOS SISTEMAS AGROINDUSTRIALES LAS AGROINDUSTRIAS EN ARGENTINA Y EL NEA Producción en docencia. Revista Geográfica Digital. IGUNNE. Facultad de Humanidades. UNNE. Año 13. № 26. Julio -Diciembre 2016. Resistencia, Chaco. En: http://hum.unne.edu.ar/revistas/geoweb/default.htm 


\section{Actividades agroindustriales en Argentina}

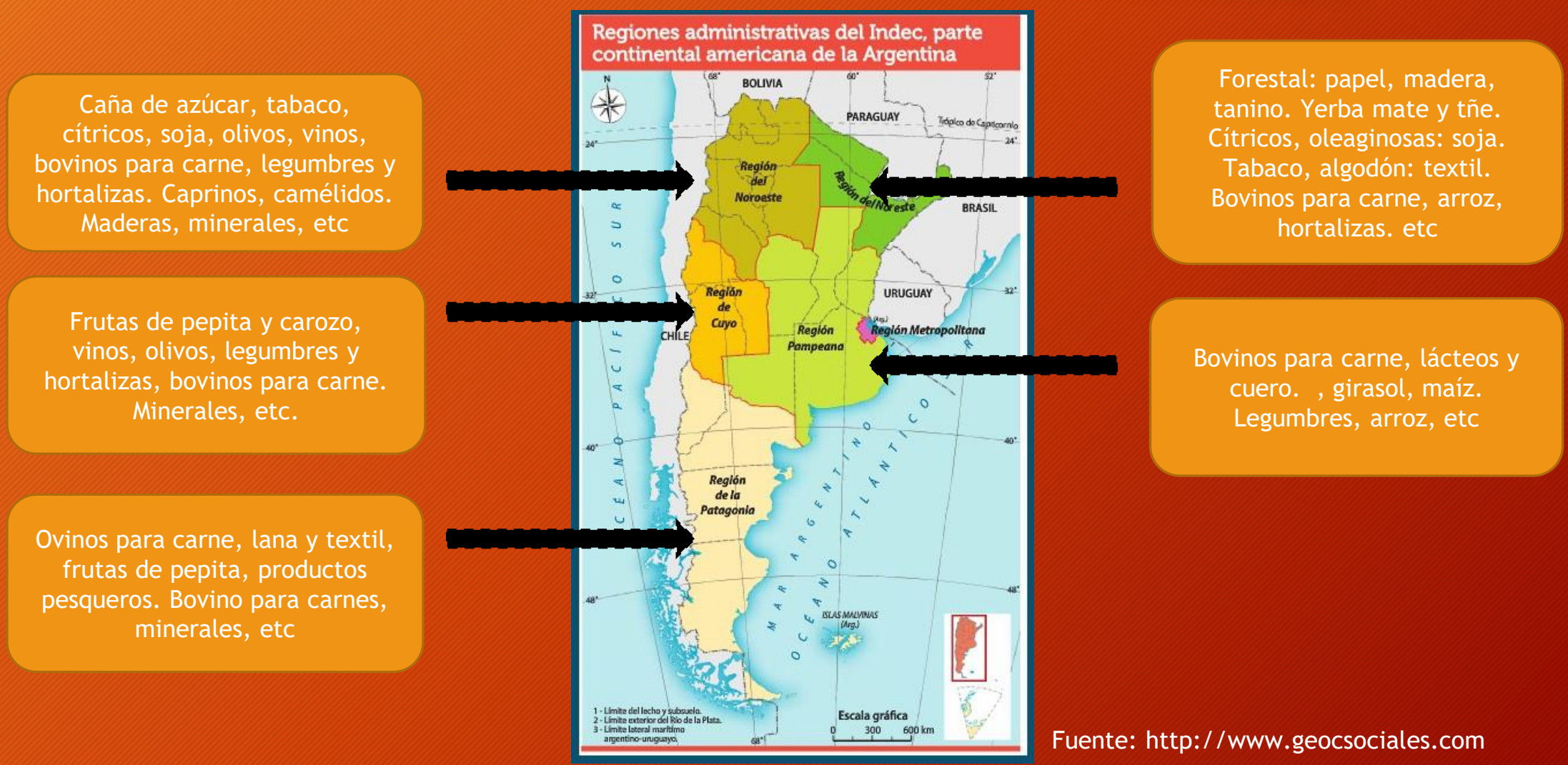

Publicado en formato digital: Prof. Alejandra H. Torre Geraldi. LOS SISTEMAS AGROINDUSTRIALES LAS AGROINDUSTRIAS EN ARGENTINA Y EL NEA Producción en docencia. Revista Geográfica Digital. IGUNNE. Facultad de Humanidades. UNNE. Año 13. № 26. Julio -Diciembre 2016. Resistencia, Chaco. En: http://hum.unne.edu.ar/revistas/geoweb/default.htm 


\section{Principales complejos productivos en Argentina y el NEA}
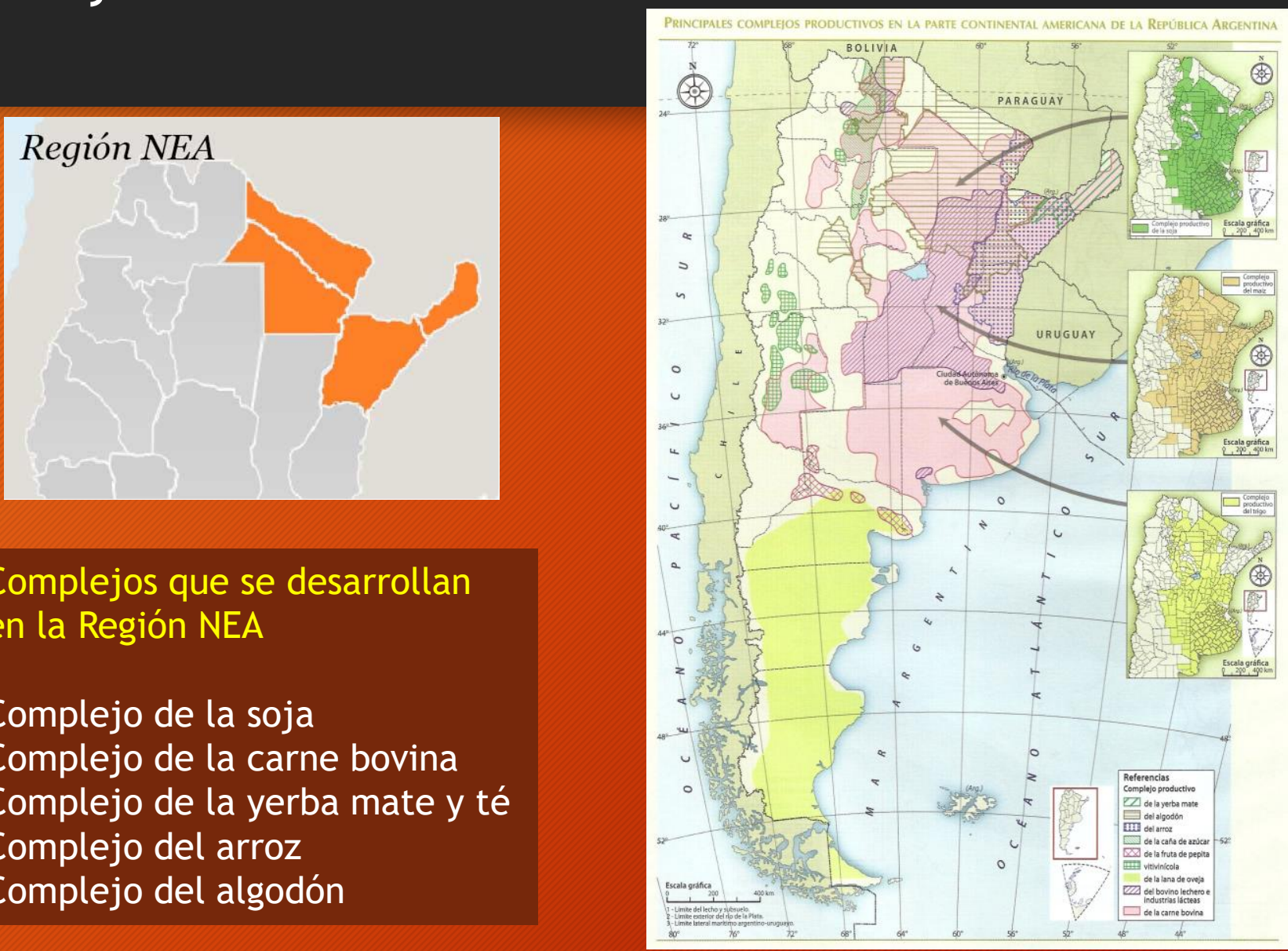

Complejos que se desarrollan en la Región NEA

Complejo de la soja Complejo de la carne bovina Complejo de la yerba mate y té Complejo del arroz Complejo del algodón

Fuente: Echeverria y Kapuz; 2012.

Publicado en formato digital: Prof. Alejandra H. Torre Geraldi. LOS SISTEMAS AGROINDUSTRIALES LAS AGROINDUSTRIAS EN ARGENTINA Y EL NEA Producción en docencia. Revista Geográfica Digital. IGUNNE. Facultad de Humanidades. UNNE. Año 13. № 26. Julio -Diciembre 2016. Resistencia, Chaco. En: http://hum.unne.edu.ar/revistas/geoweb/default.htm 


\section{El Complejo Oleaginoso Argentino}

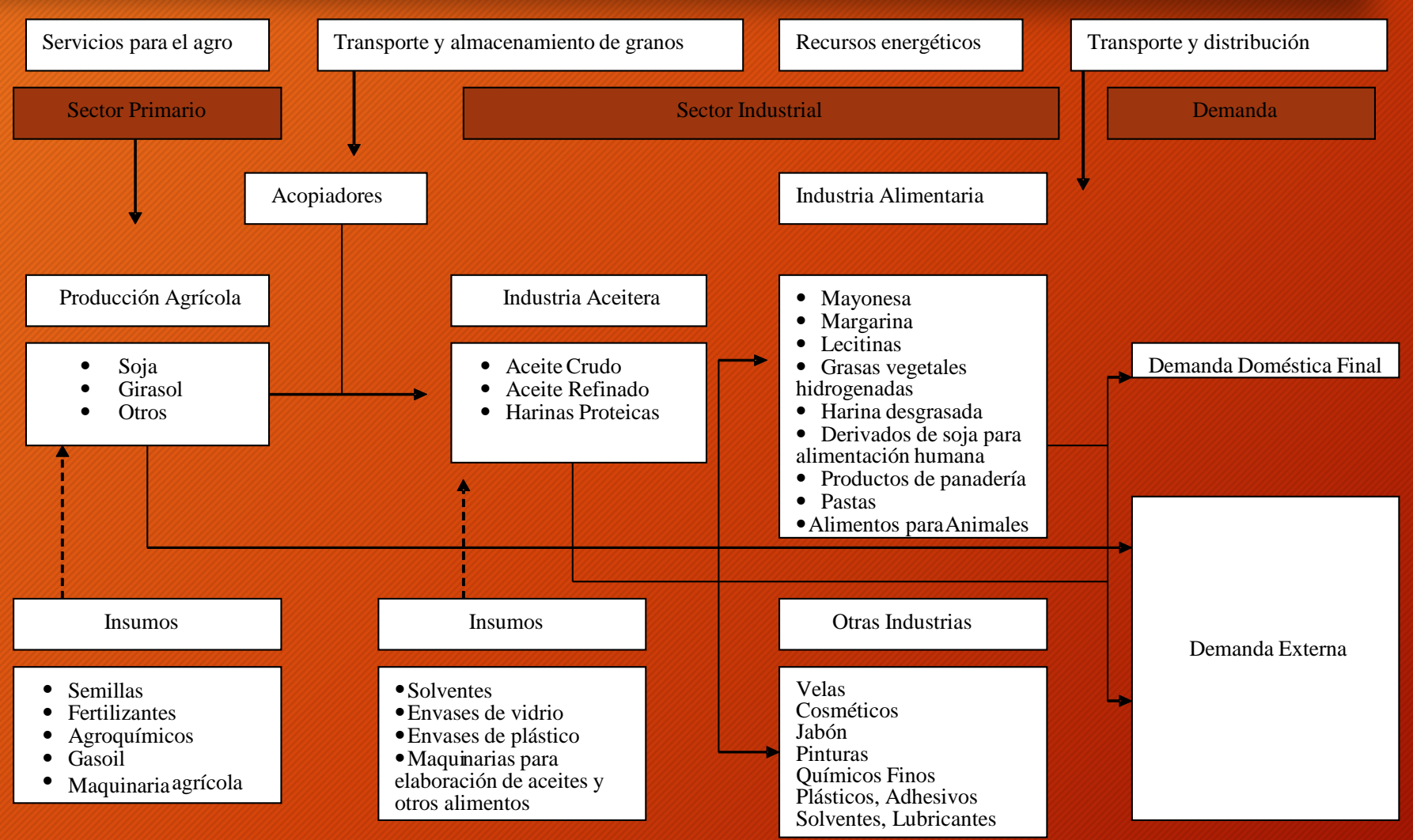

Fuente: OTERO, Gerardo (Coord.), 2002

Publicado en formato digital: Prof. Alejandra H. Torre Geraldi. LOS SISTEMAS AGROINDUSTRIALES LAS AGROINDUSTRIAS EN ARGENTINA Y EL NEA Producción en docencia. Revista Geográfica Digital. IGUNNE. Facultad de Humanidades. UNNE. Año 13. № 26. Julio -Diciembre 2016. Resistencia, Chaco. En: http:/hum.unne.edu.ar/revistas/geoweb/default.htm 


\section{Cadena de producción Bovina: El complejo de la Carne}
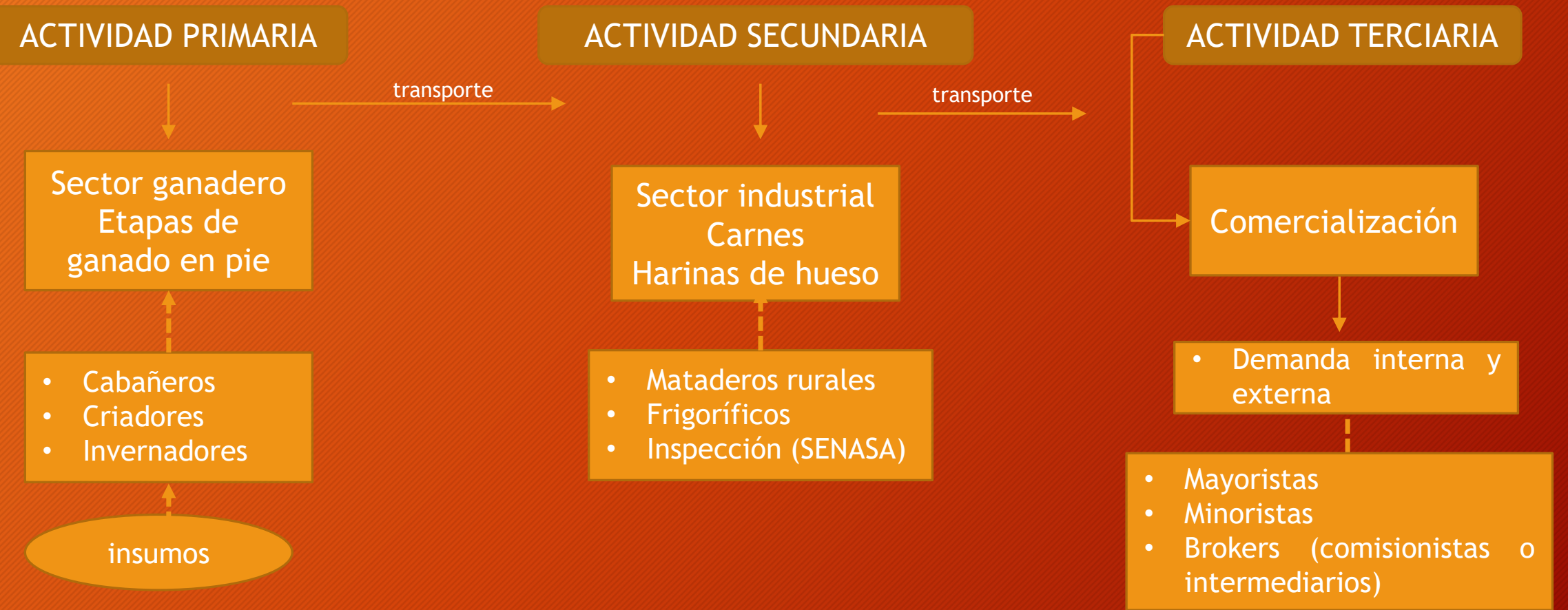

Fuente: Elaboración propia en base a Echeverria y Kapuz, 2012.

Publicado en formato digital: Prof. Alejandra H. Torre Geraldi. LOS SISTEMAS AGROINDUSTRIALES LAS AGROINDUSTRIAS EN ARGENTINA Y EL NEA Producción en docencia. Revista Geográfica Digital. IGUNNE. Facultad de Humanidades. UNNE. Año 13. № 26. Julio -Diciembre 2016. Resistencia, Chaco. En: http://hum.unne.edu.ar/revistas/geoweb/default.htm 


\section{Complejo de la caña de azúcar}

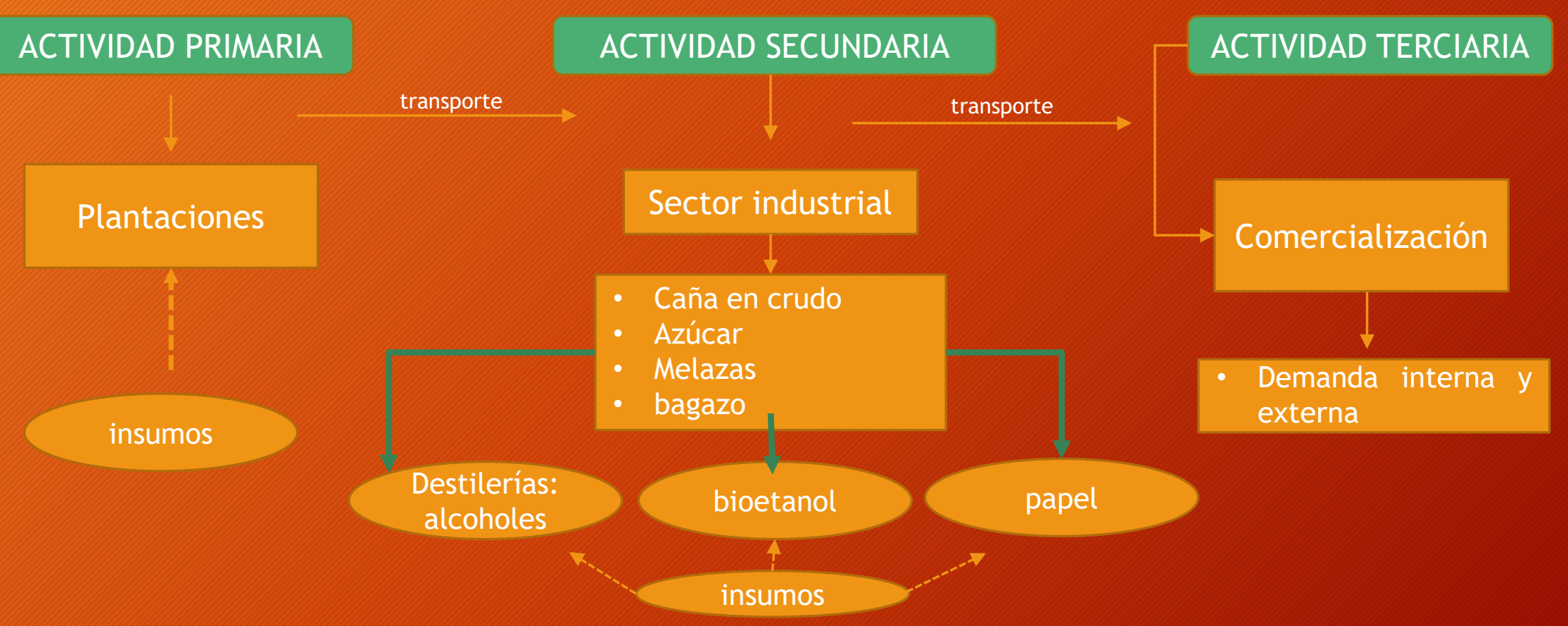

Fuente: Elaboración propia en base a Echeverria y Kapuz, 2012.

Publicado en formato digital: Prof. Alejandra H. Torre Geraldi. LOS SISTEMAS AGROINDUSTRIALES LAS AGROINDUSTRIAS EN ARGENTINA Y EL NEA Producción en docencia. Revista Geográfica Digital. IGUNNE. Facultad de Humanidades. UNNE. Año 13. № 26. Julio -Diciembre 2016. Resistencia, Chaco. En: http://hum.unne.edu.ar/revistas/geoweb/default.htm 


\section{Complejo agroindustrial del algodón}

\section{ACTIVIDAD PRIMARIA}

\section{ACTIVIDAD SECUNDARIA}

transporte
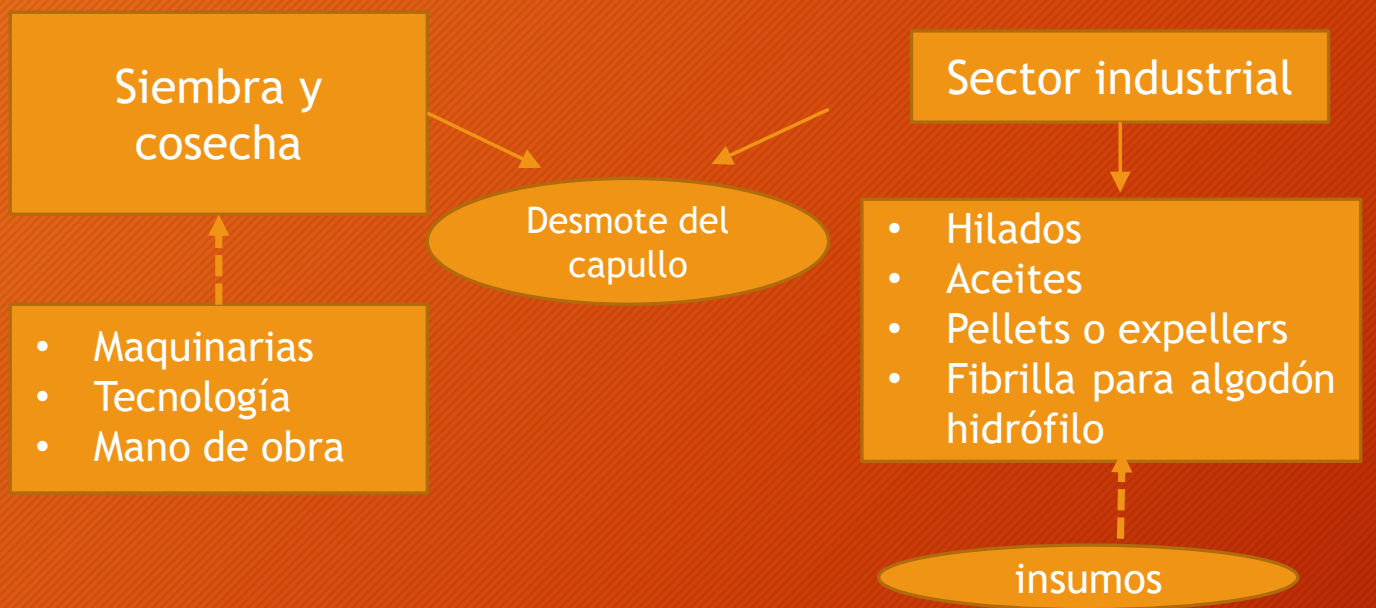

\section{ACTIVIDAD TERCIARIA}

\section{Comercialización}

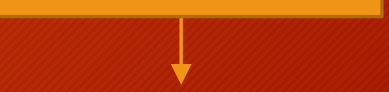

- Demanda interna y externa

- Algodón en bruto

- Fibra

- Semillas

- hilados

Fuente: Elaboración propia en base a Echeverria y Kapuz, 2012.

Publicado en formato digital: Prof. Alejandra H. Torre Geraldi. LOS SISTEMAS AGROINDUSTRIALES LAS AGROINDUSTRIAS EN ARGENTINA Y EL NEA Producción en docencia. Revista Geográfica Digital. IGUNNE. Facultad de Humanidades. UNNE. Año 13. № 26. Julio -Diciembre 2016. Resistencia, Chaco. En: http://hum.unne.edu.ar/revistas/geoweb/default.htm 


\section{El ciclo productivo de la Yerba Mate}

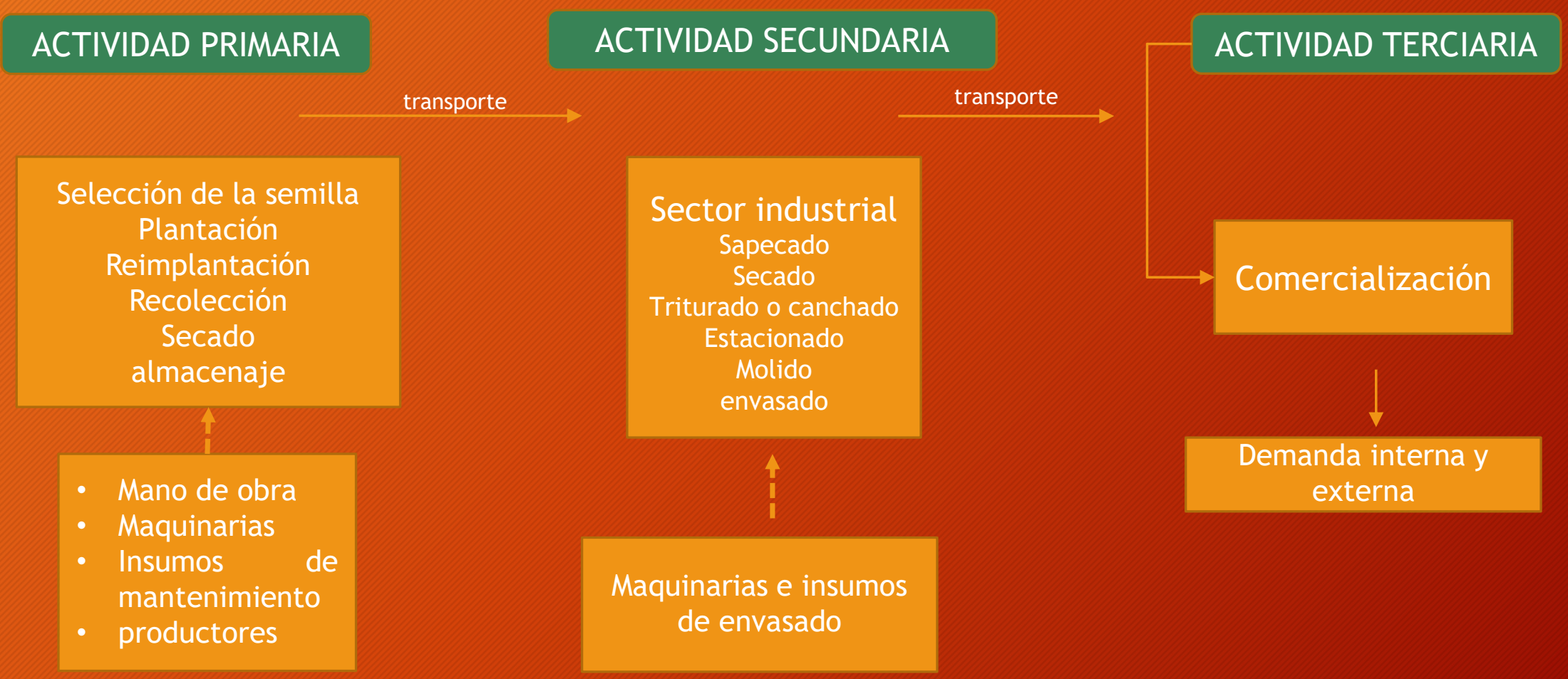

Fuente: Elaboración propia en base a Echeverria y Kapuz, 2012.

Publicado en formato digital: Prof. Alejandra H. Torre Geraldi. LOS SISTEMAS AGROINDUSTRIALES LAS AGROINDUSTRIAS EN ARGENTINA Y EL NEA Producción en docencia. Revista Geográfica Digital. IGUNNE. Facultad de Humanidades. UNNE. Año 13. № 26. Julio -Diciembre 2016. Resistencia, Chaco. En: http://hum.unne.edu.ar/revistas/geoweb/default.htm 


\section{Actores sociales que participan en el circuito productivo}

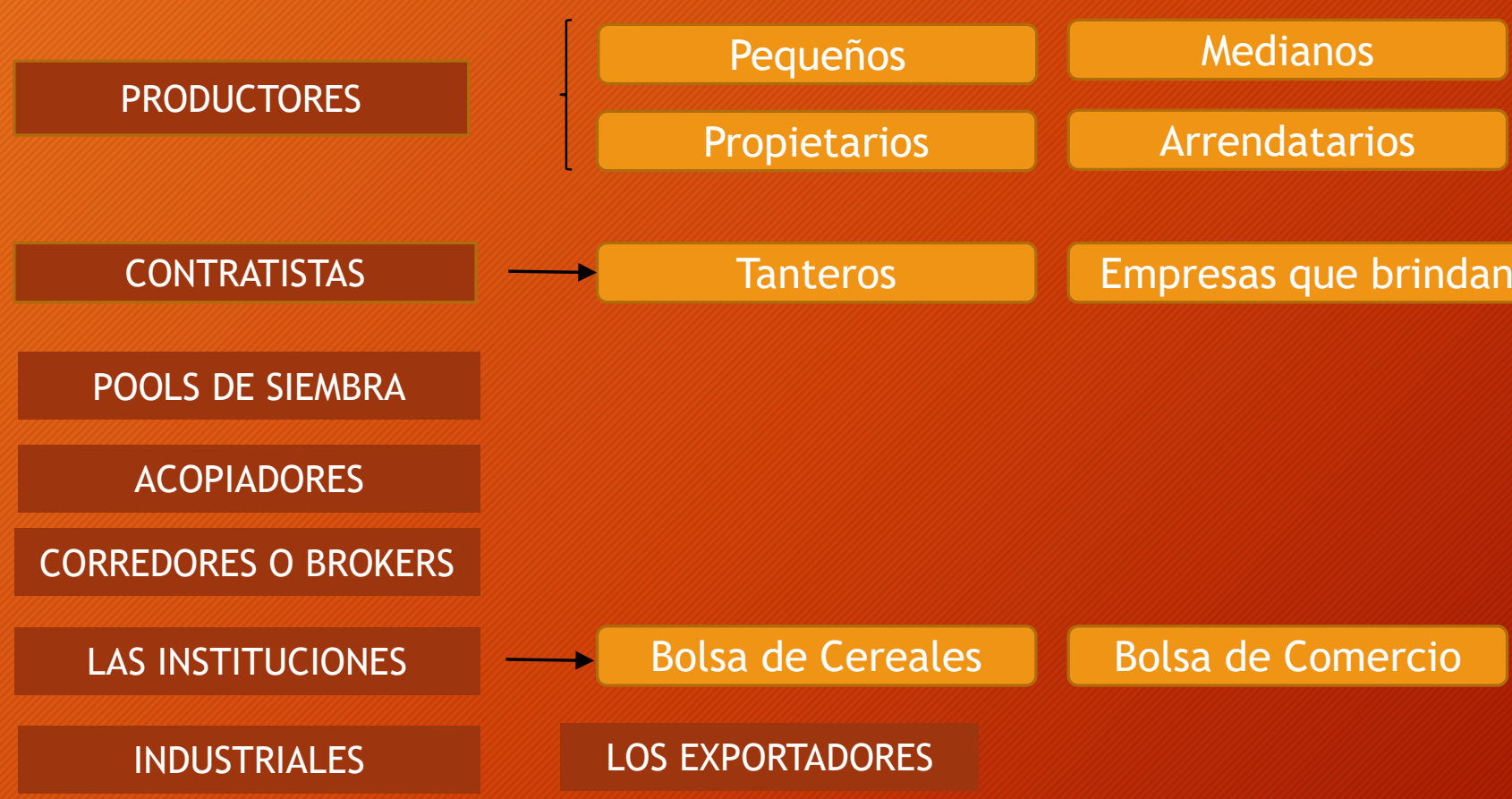

Fuente: Elaboración propia en base a Echeverria y Kapuz, 2014.

Publicado en formato digital: Prof. Alejandra H. Torre Geraldi. LOS SISTEMAS AGROINDUSTRIALES LAS AGROINDUSTRIAS EN ARGENTINA Y EL NEA Producción en docencia. Revista Geográfica Digital. IGUNNE. Facultad de Humanidades. UNNE. Año 13. № 26. Julio -Diciembre 2016. Resistencia, Chaco. En: http://hum.unne.edu.ar/revistas/geoweb/default.htm 


\section{Empresas agroindustriales que participan en las cadenas de valor en Argentina}

- Participan en la actividad agroindustrial, ya sea por ser productoras agropecuarias, elaboradoras de alimentos o fabricantes de insumos o tecnología para el campo.

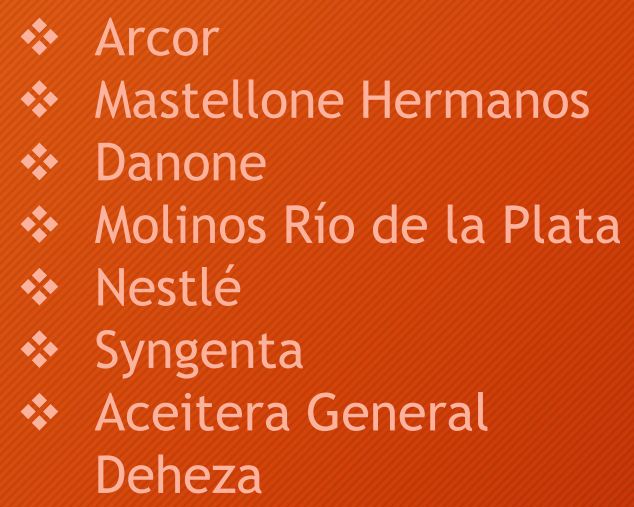

* Arcor

* Mastellone Hermanos

Danone

* Molinos Río de la Plata

Nestle

* Syngenta

Deheza

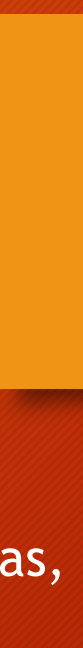




\section{BIBLIOGRAFÍA}

- ALVARAdO LEDESMA, Manuel. (2003) La Argentina agricola, un país que niega su destino. Editorial Temas. Buenos Aires .

- AlVARAdO LedeSMA, Manuel. (2004) Agronegocios. Empresa y Emprendimiento. Editorial El Ateneo. Buenos Aires.

- ALVARAdO LEDESMA, Manuel. (2008) ¿Por qué despreciamos el agro? Historia de un conflicto. Colección caminos de la Argentina. Editorial El Ateneo. Argentina.

- CEPAL. (1998) Revista de la CEPAL No66. Naciones Unidas. Santiago de Chile. En la Web: http://www.cepal.org/es/publicaciones/37944-revista-de-lacepal-no66

- DA SILVA, Carlos A. ; BAKER Doyle; SHEPHERD, Andrew W.; JENANE, Chakib y MIRANDA DE LA CRUZ, Sergio (2013) Agroindustrias para el desarrollo. Organización de las Naciones Unidas para la Alimentación y la Agricultura (FAO) Viale delle Terme di Caracalla, 00153, Roma, Italia. En la Web: www. fao.org/ag/ags

- ECHEVERRÍA, Marñia Julia y KAPUZ, Silvia. (2012) Geografía social y económica de la Argentina. Serie Plata. Editorial A-Z. Argentina.

- ECHEVERRíA, Marñia Julia y KAPUZ, Silvia. (2014) Geografía de la Argentina. Serie Plata. Editorial A-Z. Argentina.

- GRAS, Carla y HERNÁNDEZ, Valeria (Coord) (2009) La Argentina rural. De la agricultura familiar a los agronegocios. Editorial Biblos Sociedad. Argentina.

- HECKER, Eduardo (Coord.). (1999) Reporte Industrial 1999. La industria argentina ante los desafíos del próximo siglo. Centro de Estudios para la Producción, Secretaría de Industria, Comercio y Minería. Buenos Aires. En la Web: http://www.oocities.org/wallstreet/exchange/1033/ri99.htm

- NEIMAN, Guillermo (comp) (2001) El Trabajo de Campo. Producción, tecnología y empleo en el medio rural. Ed. Ciccus. Buenos Aires.

- OBSCHATKO, Edith. (1997). Articulación productiva a partir de los recursos naturales. El caso del complejo oleaginoso argentino. En: Documento de Trabajo $N^{\circ}$ 74. CEPAL. Buenos Aires.

- OTERO, Gerardo (Coord.) (2002) Cluster productivo en la Provincia de Buenos Aires (2 Parte) En: Cuadernos de Economía Nº 64 . Ministerio de Economía de la Provincia de Buenos Aires. En la Web: http://www.ec.gba.gov.ar/areas/estudios_proyecciones/Archivos/Cuaderno64.pdf 